\title{
Crenças dos professores e formação docente
}

\begin{abstract}
Resumo: Este estudo discute o conceito de crenças e sua influência na prática pedagógica dos professores. Sistematiza algumas de suas peculiaridades, a partir da literatura específica, contribuindo no estudo dessa temática ao acrescentar três novas características construídas através da análise da pesquisa de campo com educadores. Enfoca, ainda, a necessidade dos cursos de formação docente atentarem para a importância das crenças na construção do processo identitário dos professores, pois tal processo não ocorre somente através do acesso às teorias pedagógicas.

Palavras-chave: Professores - Formação. Crença. Prática de ensino. Ludicidade.
\end{abstract}

Diante das inúmeras teorias que buscam compreender a práxis pedagógica do professor, este artigo, fruto da leitura reflexiva e da pesquisa de campo com professores das séries iniciais do Ensino Fundamental, opta por discutir o conceito de crença e sua influência no trabalho do educador. Tal escolha justifica-se por considerarmos que conhecer, discutir e compreender as crenças contribui para ampliar as discussões no campo educacional, de forma, inclusive, a possibilitar um repensamento das lacunas existentes na abordagem da prática pedagógica.

Em relação às pesquisas sobre as crenças no campo pedagógico, é importante salientar que somente nos últimos anos têm sido compreendidas como relevantes nos estudos sobre os paradigmas do/a professor/a, pois as perspectivas que não se encaixavam no racionalismo e na tecnocracia não eram fáceis de serem valorizadas e respeitadas nas discussões acadêmicas.

No tópico a seguir, buscamos esclarecer a definição de crenças que é utilizada neste trabalho, inclusive, discutindo, também, alguns conceitos relacionados, tais como: saber, conhecimento, representação e valores, dentre outros. O objetivo é mostrar a relação entre esses conceitos e as crenças, suas semelhanças e diferenças, de forma a configurar o que se propõe este artigo: a compreensão do conceito de crenças.

\section{Saberes, representações, crenças ... Quando utilizamos esses termos estamos falando da mesma coisa? \\ Essa tentativa de definição não é algo fácil, pois os estudiosos dessa área assumem atitudes diferentes: enquanto uns fundem os termos, outros optam por distingui-los. Além do mais, a}

Ima Maria Fernandes Soares

Professora Assistente do Departamento de Ciências Humanas Universidade do Estado da Bahia.

Nelson Rui Ribas Bejarano Professor Adjunto IV do Instituto de Química Universidade Federal da Bahia

R. Faced, Salvador, n.14, p.55-71, jul./dez. 200855 
literatura sobre esse assunto, no Brasil, ainda é escassa, e os livros que abordam essa temática, em geral, disponibilizam uma parte pequena para essa discussão.

Ainda em relação ao termo crença, apesar da sua utilização e importância no terreno da Antropologia, da História, da Psicologia, da Filosofia e da Pedagogia, ainda não se encontra bem definido, haja vista que, como anota Rita Silva (2000, p. 31), "[...] ser um termo vago que vem diluído em outros termos e dentro de diversas teorias". Ela ainda complementa que "[...] às vezes ele pode ser circular e aparecer em diversos enfoques, com linguagens diferentes, significando a mesma coisa e, às vezes, ele vem acompanhado de outros termos para explicar os comportamentos ou tipos de pensamento" Rita Silva (2000, p. 31). A opção dessa autora é utilizar os conceitos saber, concepções, noções e crenças como sinônimos.

Com esse mesmo objetivo de esclarecer o conceito de crença, Pajares (1992) aponta inúmeros outros encontrados na literatura, que podem ser redutíveis ao conceito de crenças. São esses os destacados pelo autor:

[...] atitudes, valores, julgamentos, axiomas, opiniões, ideologia, percepções, concepções, sistemas conceituais, pré-concepções, disposições, teorias implícitas, teorias explícitas, teorias pessoais, processos mentais internos, estratégias de ação, regras da prática, princípios práticos, perspectivas, repertórios de entendimento, estratégia social. (PAJARES, 1992, p. 309)

Assim, o termo saber não é considerado por esse autor tendo o mesmo sentido de crença, diferentemente de Rita Silva (2000).

Em relação à equivalência entre crença e teoria implícita, destacada por Pajares (1992, p. 309), observamos, na análise de Zabalza (1994, p. 41), que ele considera a teoria implícita mais abrangente do que as crenças, inclusive abarcando um grupo de crenças.

Diante da análise feita até agora, percebemos que os autores convergem e divergem, ao mesmo tempo quanto aos termos utilizados ao compreenderem que alguns termos podem ser considerados sinônimos, enquanto outros autores concebem que não. Neste texto, utilizamos enquanto sinônimos de crenças os vocábulos convicções e "certezas".

Outra discussão importante para a compreensão das crenças é a diferenciação feita por Ramos (1997), a partir de Ortega y

56 R. Faced, Salvador, n.14, p.55-71, jul./dez. 2008 
Gasset (1957), em relação às ideias e às crenças. Para esses autores, há uma distância insuperável entre ambas, tendo as ideias o papel de se situar onde não existem crenças firmes: nas dúvidas. Ramos (1997, p. 20) acrescenta, ainda, que "[...] embora as crenças sejam do sujeito, elas atuam num grau de consciência que não se comparam a meras opiniões ou ideias sobre algo.", haja vista que as ideias são representações virtuais e imaginárias do sujeito frente à realidade, enquanto as crenças correspondem à realidade radical do sujeito.

Um termo que geralmente acompanha as crenças, e merece ser analisado, diz respeito ao conceito de valores. Por valor, entendemos o julgamento que se faz, conscientemente, de alguma coisa ou algo de forma a orientar escolhas e atitudes. A importância dessa análise justifica-se na diferenciação de Teixeira (2002), quando demarca que alguns valores se tornam crenças e, assim, deixam de ser conscientes. Vejamos como a autora aclara esse assunto:

Se um valor orienta, repetidamente e com sucesso, a solução de situações importantes da organização, o grupo passa por um processo de aprendizagem compartilhada que lhe confere convicções a respeito. Ao se tornar crença, o valor passa a ser tomado com segurança e progressivamente assume um grau de inconsciência, tornando-se um hábito ou automatismo. Nem todo valor sofre essa transformação. Somente os valores susceptíveis de validação social ou física, e que continuam funcionando na solução dos problemas do grupo, transformamse em concepções. (TEIXEIRA, 2002, p. 24)

A partir desta afirmação, acrescentamos que o mesmo acontece com alguns saberes tornados cristalizados e que conseguem intervir nas atitudes dos/as professores.

Mais uma diferenciação que fazemos é entre as crenças e as representações. Como relata Tomaz Tadeu Silva (2000, p. 97), a representação é um "Conceito central em campos como a Filosofia e a Psicologia Social, nos quais tem conotações bastante diferentes.". Um pouco dessa utilização do termo com perspectivas diferentes pode ser constatado na discussão de representação elaborada por Penin (1994, p. 32), quando esclarece que a sua abordagem não envereda pelas discussões da Teoria das Representações Sociais, elaborada por Moscovici (1961), por considerá-la insuficiente para o desvelamento do seu estudo. Sobre isso, ela compreende que: "[...] Assim, entendo que as representações sociais ou representações

R. Faced, Salvador, n.14, p.55-71, jul./dez. $2008 \mathbf{5 7}$ 
coletivas têm uma existência no social independente de cada sujeito particular, isto é, elas estão no social mesmo antes do nascimento do sujeito. (PENIN, 1994, p. 32)

O sentido atribuído às representações que Penin (1994) escolhe para sustentar o seu trabalho converge para a compreensão de crenças que norteia este estudo, no sentido de não negar a influência do coletivo nas crenças, mas optar por focar essa compreensão em cada sujeito, nas suas vivências, na sua forma de ver, sentir e se posicionar no trabalho que realiza. Nesse sentido atribuído pela autora, podemos afirmar que crenças e representações têm o mesmo significado.

A importância atribuída às representações, pela autora, converge às crenças, no sentido de que os/as professores também estão envolvidos com suas convicções, inclusive utilizando-as como filtros para a assimilação dos conhecimentos científicos.

Outro termo que merece ser discutido nessa tentativa de diferenciação é saber, e o observamos na discussão feita por Fiorentini, Souza Júnior e Melo (1989); Perrenould (2001); Penin (1994) e Tardif (2002) sobre saberes, elementos que convergem com a nossa compreensão de crenças. Tardif (2002, p. 49), por exemplo, ao discutir os saberes experienciais, diz que eles "[...] formam um conjunto de representações a partir das quais os professores interpretam, compreendem e orientam sua profissão e sua prática cotidiana em todas as suas dimensões".

Com essa declaração do autor, notamos que ele assinala a interferência das crenças na elaboração dos saberes experienciais dos/as professores/as, no entanto, esse mesmo autor, convergindo com estudiosos do campo das crenças, tais como Rita Silva (2000) e Bejarano (2001), também expressa a dificuldade dessa diferenciação, diante da subjetividade dos termos, dos aspectos em comuns entre eles, etc. Tardif (2002, p. 298), fundamentado em Raymond (1993), demonstra essa dificuldade ao questionar se de fato trata-se de "saberes" ou de crenças, habitus no sentido de Bourdieu, esquemas de ação e de pensamento interiorizados no âmbito da socialização profissional ou mesmo durante a histórica escolar ou familiar dos professores.

Outro termo difícil de ser distinguido das crenças, quando nos propomos a compreendê-lo na prática, é conhecimento. Além do mais, no plano teórico, observamos, ainda, que alguns autores utilizam alguns termos para abranger os conhecimentos mais

58 R. Faced, Salvador, n.14, p.55-71, jul./dez. 2008 
experienciais, tais como Sadalla (1998), que fala de "conhecimentos práticos".

Conhecimento científico é aqui entendido como as produções das diversas ciências, mediante seus diferentes métodos, tendo como característica o rigor e a comprovação. O conhecimento se refere às elaborações sistematizadas e, assim, está ligado mais fortemente à racionalidade. Outro aspecto do conhecimento é que ele é histórico, ou seja, ele se modifica desde a elaboração de novos conhecimentos.

A relação entre conhecimento e crença, ocorre, por exemplo, quando o primeiro é valorizado e aceito por uma comunidade e os seus argumentos são convincentes; mesmo quando não consegue modificar uma crença, ao menos, ele pode, por vezes, incomodar o sujeito nas suas "certezas".

No que se refere, ainda, à diferenciação desses termos, é importante esclarecer que as ciências também têm suas convicções e que nascem das crenças e suposições aceitas em um determinado momento por uma comunidade. Sobre essa relação, Sarmento (1994, p. 56) é claro ao afirmar que: "[...] São esses valores, crenças e suposições que se articulam de forma a configurar um paradigma, no interior do qual se opera a investigação científica."

Ensaiamos uma argumentação que se remete à diferença entre crença e conhecimento. Talvez essa seja a tarefa mais árdua desse estudo. Dito de maneira bastante simplificada, conhecimento seria uma forma de crença hiperjustificada, analogamente crenças são formas de conhecimento que abdicam de justificações. Sempre que nos aproximamos de alguma forma de conhecimento o fazemos imbuídos de nossas crenças, isso acaba causando a impossibilidade prática da existência de um "conhecimento puro" isento de crenças.

Diante desse questionamento do supracitado autor, gostaríamos de fechar esse tópico onde introduzimos algumas diferenciações entre o conceito de crença e outros conceitos correlatos, e onde pudemos perceber que não há muito acordo, entre os teóricos, quanto a um conjunto de conceitos que aparentemente se remeteriam ao conceito de crenças, afirmando que estudar crenças educacionais é se aproximar do pensamento e das ações dos professores que sabemos que não são movidos apenas pelo conhecimento, mas também e, sobretudo por suas crenças educacionais, mas também de homem, de mundo, dentre outras.

R. Faced, Salvador, n.14, p.55-71, jul./dez. 200859 
Com o intuito de continuarmos elucidando o conceito de crenças, sistematizamos nove características elaboradas por autores que discutem tal assunto. Vejamos, agora, tais características.

\section{Algumas características de crenças sistematizadas a partir da literatura na área}

No que se refere à definição utilizada nesse estudo sobre crenças, ela é decorrente de alguma de suas características apresentadas pelos autores e pela pesquisa empírica que realizamos. Nesse sentido, é que optamos por iniciar discutindo as nove características que sistematizamos sobre as mesmas para depois apresentar a definição por nós construída.

As crenças são elaborações individuais, mas produzidas a partir do contexto sociocultural

Os autores que embasam essa discussão sobre crenças, apesar de esclarecerem que se trata de uma elaboração individual, enfatizam também a influência do contexto sociocultural na formulação das crenças, como, Bejarano (2001), Ramos (1997) e Rita Silva (2000). É nessa direção que Ramos (1997, p. 19) destaca que "[...] a subjetividade também tem uma origem coletiva, pois a pessoa se desenvolve a partir das circunstâncias que vivenciou, isto é, dos valores, das crenças, dos usos e costumes do grupo à sua volta.

A começar desses autores, compreendo que as crenças são concepções individuais, mas que extrapolam essa individualidade, justamente por se inserir na convivência coletiva, com outros membros da sociedade, que são influenciados e influenciam na consecução do que podemos chamar de "realidade" e, portanto, também das crenças.

Outro aspecto social que interfere na elaboração das crenças é a linguagem. Autores como Vigotsky (1989) e Bakhtin (1997) entendem que os elementos sociais interferem na formulação do conhecimento e da subjetividade e são mediados pela cultura e pela linguagem. Nesse sentido, Ramos (1997, p. 364) declara que: "[...] Ao recebermos a linguagem, recebemos seus significados e a opinião pública nela incrustada - pois encontramo-nos imersos em seus valores e crenças." 
Por se tratarem de criações socioculturais, as crenças também são históricas, no sentido de que provêm dos elementos presentes em um contexto sociocultural específico. As crenças resultam da relação do sujeito com sua profissão, dos seus valores pessoais, da relação que estabelece com sua classe social, dos seus interesses, da sua posição diante do mundo, da sua opção política, enfim, da sua história de vida, que resulta da análise que ele faz do real, que é retocado e transformado considerando o que o sujeito pensa que seja ou deva ser. Em se tratando, especificamente, das convicções dos/as professores/as, Ramos (1997, p.3) concebe que a desvalorização profissional, salarial e a relativa à sua competência educativa também interferem na construção das mesmas.

\section{As crenças nos dão segurança}

Um aspecto que interfere para que as crenças possibilitem o sentimento de segurança é que elas dão sentido às ações e às coisas. Assim constituem uma forma de entender e explicar o mundo. Como declara Ramos (1997, p. 20): "[...] Elas formam o chão dos nossos caminhos sem que nos perguntemos se está lá ou não, pois simplesmente andamos sobre ele."

Quando nos propomos a compreender como esse "chão firme" se encontra presente no trabalho pedagógico, é possível observar, pelas conclusões de alguns autores, tais como Arroyo (2000), Rita Silva (2000), Teixeira (2002), que a rotina oferece essa segurança psicológica ao/à professor/a, pois estabelece um padrão de comportamento que reduz a necessidade de refletir sobre as diversas situações pedagógicas. Além do mais, as "certezas" que os/as professores/as têm e guiam seu trabalho os tranquilizam diante de um mundo cheio de inovações e transformações, sem esquecer, ainda, que as teorias educacionais não explicam as diversas situações que os professores vivenciam na sua prática pedagógica. Sobre isso, Perrenoud (2001, p. 154) entende que: "[...] Quando as teorias eruditas não existem, é preciso agir." Muitas vezes, a reflexão só ocorre depois de tomada certa atitude.

\section{As crenças estão organizadas como um sistema que cria ou reforça outras crenças}

O terceiro aspecto das crenças, apresentado por autores como Ramos (1997) e Bejarano (2001), refere-se ao fato de que elas estão estruturadas em rede, formando um sistema que produz ou reforça 
outra. Dessa forma, é possível destacar o fato de que existem convicções primárias e secundárias que se conectam de forma a garantir a sobrevivência umas das outras. Com essa compreensão, percebemos que algumas crenças têm maior força do que outras, talvez pelo seu caráter de "verdade" para o sujeito.

Esse sistema de crenças é formado mediante as combinações de informações, interpretações e experiências, que vão se organizando com outras. Assim, uma crença que não tenha uma relação mais direta com os fatos pode interferir no surgimento de convicções com a mesma característica, pois, para o sujeito, ela corresponde ao que efetivamente existe, mas também pode se relacionar com outra contraditória, porque a "verdade" não é a principal preocupação de uma crença.

As crenças não têm uma preocupação primordial com a "verdade"

As crenças são absolutamente livres, pois elas, ao contrário do conhecimento, não precisam de comprovações para serem aceitas. Elas se sustentam no que se acredita. Nesse sentido, Ramos (1997, p.20) garante que "[...] elas são pressupostos sobre os quais construímos nossas verdades."

Moreira (2002, p. 33, grifo do autor) também contribui na compreensão dessa característica das crenças, ao defini-las como "[...] opiniões acerca do estado objetivo do mundo. Aquilo em que as pessoas crêem pode ser verdadeiro ou não, mas geralmente o que interessa aqui é o que a pessoa pensa ser verdadeiro."

Diante dessa característica, não podemos esperar coerência, unidade teórica e validação das crenças, pois elas são elaboradas sem uma reflexão mais sistematizada. Além do mais, diferentes elementos compõem o trabalho pedagógico. São esses vários elementos que delineiam o sincretismo também das crenças educacionais.

As crenças são elaborações que não se limitam a racionalidade

A opacidade das crenças é um aspecto abordado por vários dos teóricos que estudam essa temática. Esse velamento das crenças ocorre diante do fato de serem elaborações internas e por vezes inconscientes. É nesse sentido que Ramos (1997, p. 20 grifos do autor), afirma que "[...] As crenças constituem o discurso do sujeito, mas não aparecem no mesmo de uma maneira explícita. Estão presentes de uma forma sutil e velada." 
É esse mesmo autor que evidencia, entretanto, que essa opacidade não inviabiliza o acesso às crenças dos sujeitos. Cabe ao pesquisador atentar para este fato de forma a detectar os elementos que realmente constituem crenças.

Por não se limitar à racionalidade, as crenças se tornam veladas para o próprio sujeito, que não se conscientiza de muitas crenças que engendrou na sua trajetória, inclusive, podendo assegurar que não as possui. Isso ocorre porque, como declara Martins (1998, p. 96), "A crença fica pelos meandros da subconsciência, nem sempre é muito clara, nem sempre é muito visível." Já Ramos (1997), a partir de Ortega y Gasset (1957, p. 2122), assegura que as crenças são constituídas de pressupostos inconscientes. Esse caráter inconsciente das crenças não significa, para o autor, que não haja nenhuma forma de reflexão e, nesse sentido, ele salienta que "[...] Normalmente não agimos 'fora de nós mesmos', com atos reflexos. Normalmente pensamos - mesmo que brevemente - na maior parte das atitudes que vamos tomar." Essa reflexão ocorre pela subjetividade de cada um, da sua forma de viver, ser e sentir o mundo. Assim, o juízo que as crenças fazem é parcial e pode, muitas vezes, ser equivocado.

Diante da análise que fizemos da discussão dos autores, é possível concluir que algumas crenças são mais claras, apresentando, inclusive, aspectos mais racionais e possíveis de explicar do que outras.

As crenças são saberes que se tornam sólidos e cristalizados

A cristalização das crenças ocorre a partir dos conhecimentos, saberes e valores adquiridos em um determinado período por uma pessoa e que lhe oferece segurança de tal forma que mesmo com o avanço das teorias - que podem, inclusive, discordar dessas elaborações - eles se recusam a ser modificados, especialmente se em algum momento elas thes possibilitaram resolver alguma questão. Assim, as crenças não se solidificam sem nenhuma reflexão, mas, depois que essa estagnação acontece, elas se tornam mais impermeáveis.

Nessa solidificação, a memória assume um papel importante, pois é partindo dos dados armazenados que interpretamos os fatos e estruturamos nossas crenças, no entanto, não podemos confiar nas nossas lembranças, pois elas não representam uma cópia fiel da realidade, mas a forma como absorvemos diante do nosso 
estado emocional, da posição em que ocupamos naquele contexto, dos dados que foram possíveis captar, etc. Ao mesmo tempo, a memória também contribui para inter-relacionar a nova crença com as que já foram elaboradas.

A cristalização das crenças interfere na aprendizagem de novos conteúdos, especialmente se esse conhecimento se contrapuser às crenças já constituídas.

Essa solidificação não significa, no entanto, que as crenças não poderão ser modificadas, mas que há algumas mais resistentes e outras com maiores possibilidades de serem permeadas por outras formas de conhecimento que contribuem para questionálas e transformá-las. Essas crenças mais resistentes às reformas é que Bejarano (2001) denomina de "núcleo duro" das crenças.

As crenças interferem nas atitudes

Na discussão feita por Pacheco (1995, p. 53), ele distingue esses dois termos, expressando que "Uma atitude é uma 'totalidade delimitada do comportamento em relação a alguma coisa", e crença é "o componente cognitivo da atitude". Assim, as crenças precedem e influenciam as atitudes.

Zabalza (1994) converge para esse pensamento de Pacheco (1995, p. 31), quando concebe que "A atuação dos professores é dirigida pelos seus pensamentos (juízos, crenças, teorias implícitas, etc.)." O autor, contudo, esclarece que essa conexão entre o pensamento e a conduta não se limita aos aspectos racionais, mas possui, como assegura, uma "racionalidade limitada". (PACHECO, 1995, p. 32)

Entendo que as crenças interferem nas atitudes que tomamos, mesmo quando não temos consciência do papel que elas exercem. Diante dessa relação estabelecida entre as convicções e as atitudes, é importante que as propostas que buscam modificar as posições assumidas, por exemplo, pelos profissionais da educação, no seu fazer pedagógico, não abdiquem de considerar as crenças como um aspecto relevante para a mudança de comportamento.

Essa conexão, porém, não é algo tão simples. As atitudes que os/as professores/as assumem também resultam das políticas educacionais, das teorias a que são obrigados a seguir, dentre outros. Assim, essa contradição pode ocorrer no trabalho pedagógico, também, graças ao sincretismo de saberes, 
experiências, valores, concepções que interferem no cotidiano dos professores.

Há crenças mais consistentes do que outras

Partindo da ideia de que crenças são estados mentais, isso implica que nos comprometemos com esses estados mentais de maneira diferente. Por vezes, nos apegando de forma a considerarmos como algo inquestionável, não passível de discussão nem pelo uso da razão. Aliás, essas crenças do tipo forte, que aqui chamamos de convicções, são impermeáveis ao próprio escrutínio da razão.

Já as crenças fracas, ao contrário, são aquelas que se forem questionadas de maneira adequada são passíveis de ser modificadas.

\section{As crenças podem ser modificadas}

Como demonstramos na característica anterior, as crenças tendem a cristalizar-se com o objetivo de garantir a sua sobrevivência e, por isso, dificultam a sua transformação, no entanto, não são imunes às mudanças.

Ao analisar autores como Zabalza (1994), Krüger (1986), Bejarano (2001) e Teixeira (2002), compreendemos que algumas convicções são mais vulneráveis e permeáveis a alterações, enquanto outras são mais resistentes. Essa resistência ou não dependerá da relevância assumida no sistema de crença por aquela especificamente. Bejarano (2001) posiciona-se no sentido de sinalizar a necessidade de nos empenharmos em compreendêlas, o mais cedo possível, de forma a não deixar torná-las mais robustas e resistentes ao desejo das inovações.

As crenças mais obstinadas são, no entendimento de Rita Silva (2000, p. 30), as consideradas pelo sujeito com maior validade psicológica, isso significa que "[...] somente modificará quando para ele não mais for útil e, portanto, sem validade."

As nove características acima elencadas pelos teóricos puderam ser confirmadas na pesquisa empírica, realizada com professoras das séries iniciais por Soares (2005). Durante a pesquisa, a referida autora percebeu, ao mesmo tempo, em que umas crenças se apresentavam em algumas professoras individualmente, outras se encontravam presentes em todas elas. Agora, acrescentaremos outras características constatadas após a análise da pesquisa de campo. 
(1) As características discutidas neste tópico surgiram a partir da pesquisa realizada por Soares (2005) em sua Dissertação (Mestrado) apresentada na Faculdade de Educacão da Universidade Federal da Bahia.

\section{A contribuição da pesquisa de campo no entendimento das crenças ${ }^{1}$}

A pesquisa de campo que nos possibilitou elaborar essas três características das crenças foi realizada com quatro professoras das séries iniciais do Ensino Fundamental em uma escola pública na periferia de Salvador-BA, através dos seguintes recursos metodológicos: a observação, a entrevista e a (auto)biografia. Através desses recursos, percebemos que havia características que ainda não tinham sido sistematizadas pelos autores estudados. É nesse sentido que afirmamos ser este estudo importante como contribuição teórica no campo das crenças, pois pensamos ter concorrido para ajudar a esclarecer o seu conceito, no sentido de que poderá ajudar melhor a compreensão e delimitação desse campo de estudo. São elas:

As crenças que os/as professores formulam sobre o processo pedagógico não se separam das questões pessoais, mas a ela se misturam, pois suas convicções são fruto das vivências pessoais e profissionais.

Essa característica foi percebida durante essa pesquisa de campo com as professoras, mas também por meio das conclusões elaboradas por Bejarano (2001, p. 235), em sua tese de doutoramento. Nesse trabalho, o autor percebe a influência das variáveis "menos acadêmicas" no desenvolvimento dos professores iniciantes. Por variáveis "menos acadêmicas" ele denomina, as "[...] experiências vividas por esses professores antes de ingressarem no curso de licenciatura."

Assim, percebemos que as variáveis "menos acadêmicas", a que Bejarano (2001) se refere, dizem respeito mais diretamente aos aspectos da profissão, mesmo quando ainda não ingressaram nos cursos que oferecem essa formação, como é possível constatar na análise que faz de elementos como opção pela docência e ambiente cultural familiar. Acrescentamos, nesse sentido, que as crenças profissionais envolvem componentes subjetivos que não se relacionam diretamente ao exercício profissional. Nesse sentido, defendemos a ideia de que na prática pedagógica, no que se refere aos julgamentos, explicações, interpretações e, também às atitudes tomadas a partir das crenças do/a professor, não se encontram presentes apenas as que se referem aos aspectos profissionais, 
mas também as que foram formuladas na sua trajetória pessoal. Esses aspectos também se unem para originar essas convicções, e é justamente porque essas experiências e formas de sentir e interpretar os fatos não se repetem que as crenças são individuais. Com isso acreditamos que determinados professores/as podem ter uma mesma crença, mas são diferentes as referências que constituíram aquela convicção.

Dessa forma, consideramos que as crenças, assim como os saberes dos/as professores/as, como argumenta Tardif (2002), são existenciais, no sentido de que são constituídas pelo que se acumulou em termos de experiência de vida e foram elaboradas considerando da sua forma de sentir, pensar e atuar no/sobre o mundo.

As crenças são pensadas a partir de uma interpretação parcial da realidade, mas que são usadas para explicar genericamente diferentes situações, sem um conhecimento mais sistematizado do fato.

Essa segunda característica diz respeito ao caráter de generalização das crenças. Essa propriedade ocorre diante da interpretação que generaliza algo contingente, que pode ter ocorrido somente uma vez. Essa característica é resultante do fato de que as convicções naturalizam o que parece estranho, o que, de alguma forma, está associado à característica da segurança que as crenças nos proporcionam.

Essa generalização ocorre pelo aspecto pragmático das convicções, que buscam controlar diferentes setores sem maior compreensão dos porquês, que podem ser heterogêneos. Os principais elementos da pesquisa que me fizeram perceber essa característica foram o posicionamento generalizado das professoras. Tal generalização, diante de um comportamento, fato ou experiência, por exemplo, torna-se visível quando se utiliza termos como todos e nunca. Essa marca das crenças é perigosa, porque pode nos levar a enganos, diante da questão de que a interpretação de um recorte da realidade não é a verdade em si, pois é um conhecimento parcial. Além do mais, não se reflete sobre as causas, nem tampouco sobre os efeitos dessa generalização, o que faz gerar a característica seguinte.

As crenças influenciam na criação de estereótipos. Esse aspecto, extremamente ligado a generalização, demonstra a 
dimensão ideológica das crenças, pois a estereotipação é decorrente de um conhecimento sem maior fundamentação e análise. Desse modo, perpetuam-se compreensões e comportamentos que, quase sempre, limitam ou desvirtuam determinado objeto, sujeito e práticas.

Essas crenças encontram-se permeadas por ideias negativas e/ou fechadas, sendo que, muitas vezes, são desprovidas do conhecimento real dessas questões. Mesmo sem esse conhecimento mais aprofundado, essas convicções se multiplicam, exercendo forte poder na prática pedagógica dessas professoras no momento em que norteiam o trabalho que elas realizam como se fossem a "própria realidade".

\section{Considerações finais}

Diante da discussão elaborada para efeito deste ensaio e diante do referencial sobre crenças, entendemo-las como formulações simbólicas que nos dão "certezas" subjetivas, pragmáticas, que aparecem, às vezes, de forma velada, feitas inconscientemente, mediante nossas experiências, da rotina de trabalho, da linguagem, dentre outras. As crenças determinam o pensamento e a ação do sujeito e servem como suporte em relação à realidade, ou seja, nos dão segurança, tornando-se, muitas vezes, sólidas e cristalizadas, servindo, assim, de "chão firme". Isso não quer dizer, no entanto, que não poderão ser modificadas. Como formas de compreensão e ação no mundo, ela deve ser primeiramente detectada, questionada quanto a sua validade, pois, mediante essas ações, é que poderemos efetivamente sensibilizar o sujeito que crê, para posteriormente, confrontá-lo com os conhecimentos elaborados por outras áreas, tais como a Filosofia, a Epistemologia, a Arte. A formação dos/as professores/as foi algo que se apresentou com bastante força nessa pesquisa. Constatamos que os cursos de formação docente não levam em consideração as crenças que os/as professores ou futuros/as professores guardam do seu processo identitário. Desse modo, perante a força que as mesmas exercem no trabalho que os/as professores/as realizam, muitas das teorias que são discutidas nesse período não interferem efetivamente na prática pedagógica das educadoras, porquanto as crenças selecionam os saberes que consideram relevantes. Assim, é necessário compreendermos as crenças diante da sua influência no comportamento assumido pelos professores em sala de aula. Para tanto, consideramos necessário confrontar as mesmas com as teorias existentes na área, de forma a

68 R. Faced, Salvador, n.14, p.55-71, jul./dez. 2008 
não tornar inócuo o conhecimento discutido durante esse período. Trazer à tona essas crenças, refletindo sobre elas, pode ser uma possibilidade de modificar ou, ao menos, tornar mais conscientes algumas crenças que interferem nas decisões e atitudes tomadas em sala de aula. Para tanto, é necessário aprendermos a trabalhar com as incertezas, com o desconhecido, se quisermos nos aproximar dessa complexidade que é o trabalho pedagógico.

Outro aspecto que acrescentamos é a importância dos cursos de formação não focar somente no aspecto racional do sujeito, mas também nas questões afetivas. Salientamos, ainda, a necessidade dos currículos considerarem a pesquisa como princípio formativo, para que, ao investigar a realidade escolar, possam rever a sua forma de pensar e agir no campo profissional, construindo uma postura investigativa.

O ponto fundamental para mudança das crenças é trazê-la para o nível da consciência, para assim poder avaliá-la e, se necessário, redimensioná-la. Diante do fato de as crenças serem elaboradas a partir de um contexto sociocultural, esse processo de modificação também poderá ser mais eficaz, se realizado coletivamente, mediante o questionamento, pois, como nota Ramos (1997), as crenças não são imunes a dúvidas e desequilíbrios.

Quando afirmamos a importância de um trabalho profissional diferente, que torne a práxis pedagógica do professor mais significativa para si e para os educandos, não desconsideramos que esse processo é doloroso, permeado por dúvidas, medos e conflitos, haja vista não ser fácil abrir mão das nossas certezas, presentes, há décadas, na prática dos professores. Além do mais, para tentar mudar essas crenças temos que focalizar não somente os professores, como categoria, mas é necessário atentarmos para todo o imaginário social que cristaliza um entendimento da profissão docente, que tanto influencia como é influenciado pelas convicções das professoras.

\title{
Teacher's beliefs and teacher education
}

\begin{abstract}
That study discusses the concept of faiths and its influence in the pedagogic practice of the teachers. It systematizes some of their peculiarities, starting from the specific literature, contributing in the study of that theme when increasing three new characteristics built through the analysis of the field research with educators. Besides, this study focuses the need of the courses of educational formation to look at the importance of the faiths in the construction of the teachers's identity process, because such a process doesn't only happen through the access to the pedagogic theories.
\end{abstract}

Key-words: Teachers, Training of. Faith. Educational practice. Ludicidade. 


\section{Referências}

ARROYO, Miguel G. (Org.). Da escola carente à escola possível. 3. ed. São Paulo: Loyola, 1991 (Educação Popular, n. 8)

Imagens quebradas: trajetórias e tempos de alunos e

mestres. Petrópolis, RJ: Vozes, 2004.

Oficio de mestre: imagens e auto-imagens. 6. ed.

Petrópolis, RJ: Vozes, 2000

BAKHTIN, Mikhail. Marxismo e filosofia da linguagem. 8 ed. São Paulo: Hucitec, 1997.

BEJARANO, Nelson Rui Ribas. Tornando-se professor de física: conflitos e preocupações na formação inicial. 2001. 207 f. Tese (Doutorado em Educação) - Faculdade de Educação, Universidade de São Paulo, São Paulo.

; BORTOLIERO, Simone Terezinha. Os desafios dos jornalistas científicos, cientistas e educadores em ciências no século XXI. In: SOUSA, Cidoval Morais de; FERREIRA, Jose Roberto; BORTOLIERO, Simone Terezinha (Org.). Jornalismo científico e educação para as ciências. Taubaté-SP: Cabral Editora e Livraria Universitária, 2006. v. 2, p. 17-28.

_; ___ ANDRADE, Rita de Cássia de. Imagens sobre a ciência e a tecnologia: o que pensam os professores da Rede Municipal de Salvador. In: SOUSA, Cidoval Morais de; FERREIRA, Jose Roberto; BORTOLIERO, Simone Terezinha (Org.). Jornalismo científico e educação para as ciências. Taubaté-SP: Cabral Editora e Livraria Universitária, 2006. v. 35 p. 469-486.

FIORENTINI, Dário; SOUZA JÚNIIOR, Arlindo José de; MELO, Gilberto Francisco Alves de. Saberes docentes: um desafio para acadêmicos e práticos. In: GERALDI, Corinta M. G., FIORENTINI, Dario; PEREIRA, Elisabete M. de A. (Org.). Cartografias do trabalho docente: professor(a) pesquisador(a). Campinas, SP: Mercado de Letras: Associação, 1998. (Leituras no Brasil)

KRÜGER, Helmuth. Introdução à psicologia social. São Paulo: EPU, 1986. (Temas básicos de psicologia, v. 12)

MARTINS, Maria Aparecida. Primeira lição: uma cartilha metafísica. São Paulo: Centro de Estudos Vida \& Consciência, 1998.

MOREIRA, Daniel Augusto. O método fenomenológico na pesquisa. São Paulo: Pioneira Thomson, 2002.

PACHECO, José Augusto. O pensamento e a acção do professor. Lisboa, Portugal: Porto Editora, 1995.

PAJARES, F.M. Teachers' beliefs and educational research: cleaning up a messy construct. Review of Educational Research, v. 62, n. 3, p. 307-332, 1992. 
PENIN, Sonia T. de Souza. A aula: espaço de conhecimento, lugar de cultura. Campinas, SP: Papirus, 1994. (Magistério: Formação e Trabalho Pedagógico).

PERRENOUD, Philippe. Ensinar: agir na urgência, decidir na incerteza. Tradução de Claúdia Schilling. Porto Alegre: Artmed, 2001 .

RAMOS, Eugenio Maria de França. A circunstância e a imaginação: o ensino de ciências, a experimentação e o lúdico. 1997. 390 f. Tese (Doutorado em Educação) - Faculdade de Educação, Universidade de São Paulo, São Paulo.

SADALLA, Ana Maria Falcão de Aragão. Com a palavra, a professora: suas crenças, suas ações. Campinas, SP: Alínea, 1998.

SARMENTO, Manuel Jacinto. A vez e a voz dos professores: contributo para o Estudo da Cultura Organizacional da Escola Primária. Porto, Portugal: Porto Editora, 1994. (Escola e Saberes; v. 2)

SILVA, Rita de C. O professor, seus saberes e suas crenças. In: GUARNIERI, Maria Aprendendo a ensinar. São Paulo: Autores Associados, 2000.

SILVA, Tomaz Tadeu. Teoria cultural e educação: um vocabulário crítico. Belo Horizonte: Autêntica, 2000

SOARES, Ilma Maria Fernandes. Se der a gente brinca: crenças de professoras sobre ludicidade e atividades lúdicas. 2005. 235 f. Dissertação (Mestrado) - Faculdade de Educação, Universidade Federal da Bahia, Salvador, 2005.

TARDIF, Maurice. Saberes docentes e formação profissional. Petrópolis, RJ: Vozes, 2002.

TEIXEIRA, Lucia Helena Gonçalves. Cultura organizacional e projeto de mudança em escolas públicas. São Paulo: Autores Associados; Campinas, SP: ANPAE, 2002.

VIGOTSKY, L.S. Pensamento e linguagem. 2 ed. São Paulo: Martins Fontes, 1989.

ZABALZA, Miguel Angel. Diários de aula: contributo para o estudo dos dilemas práticos dos professores. Porto: Porto Editora, 1994. (Ciências da educação, vol. 11) 